\title{
Exocytosis at the Ribbon Synapse of Retinal Bipolar Cells Studied in Patches of Presynaptic Membrane
}

\author{
Artur Llobet, Anne Cooke, and Leon Lagnado \\ Medical Research Council Laboratory of Molecular Biology, Cambridge CB2 2QH, United Kingdom
}

The distribution of exocytic sites and ion channels in the synaptic terminal of retinal bipolar cells was investigated by measuring capacitance and conductance changes in cell-attached patches of presynaptic membrane. Patch depolarization evoked capacitance and conductance increases that were inhibited by blocking $\mathrm{Ca}^{2+}$ influx or loading the terminal with EGTA. The increase in capacitance declined as the depolarization approached the reversal potential for $\mathrm{Ca}^{2+}$, indicating that it was a result of $\mathrm{Ca}^{2+}$-dependent exocytosis. The conductance increase was caused by $\mathrm{K}_{\mathrm{Ca}}$ channels that were also activated by $\mathrm{Ca}^{2+}$ influx. Two observations indicated that sites of exocytosis and endocytosis colocalized with clusters of $\mathrm{Ca}^{2+}$ channels and $\mathrm{K}_{\mathrm{Ca}}$ channels; the initial rate of exocytosis was correlated with the activation of $\mathrm{K}_{\mathrm{Ca}}$ channels, and exocytosis did not occur in the $41 \%$ of patches lacking this conductance. Electron microscopy demonstrated that there were $\sim 16$ vesicles docked to the plasma membrane at each active zone marked by a ribbon, but vesicles were also attached to the rest of the membrane at a density of $1.5 / \mu \mathrm{m}^{2}$. The density of ribbons was $0.10 \pm 0.02 / \mu \mathrm{m}^{2}$, predicting that $\sim 43 \%$ of cell-attached patches would lack an active zone. The density of $\mathrm{Ca}^{2+}$ channel clusters assayed by capacitance and conductance responses was therefore similar to the density of ribbons. These results are consistent with the idea that $\mathrm{Ca}^{2+}$ channel clusters were colocalized with ribbons but do not exclude the possibility that calcium channels also occurred at other sites. The wide distribution of vesicles docked to

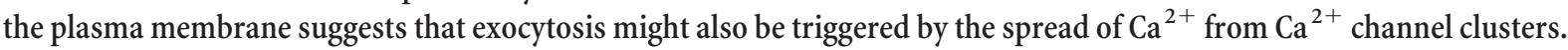

Key words: exocytosis; synaptic terminal; capacitance; calcium; vesicle; endocytosis

\section{Introduction}

Retinal bipolar cells signal light by graded changes in membrane potential and support both phasic and tonic neurotransmitter release (Lagnado et al., 1996; Mennerick and Matthews, 1996). Other sensory neurons that signal a stimulus with a graded voltage signal, such as photoreceptors and hair cells, also support these fast and slow modes of exocytosis (Rieke and Schwartz, 1994; Moser and Beutner, 2000). These sensory synapses release transmitter continuously in response to maintained depolarization and exhibit several structural differences compared with phasic synapses, in which the voltage signal controlling exocytosis is a brief action potential (Burns and Augustine, 1995). Neurons generating graded voltage signals have a characteristic osmiophilic structure at the active zone called a ribbon or dense body, and vesicles are found both attached to the ribbon and docked to the plasma membrane immediately below (Gray and Pease, 1971; von Gersdorff et al., 1996; Lenzi et al., 1999). Synapses supporting continuous transmitter release also contain large numbers of vesicles that are not associated with the active zone, and many individual vesicles appear to be docked at sites remote from ribbons (Lenzi et al., 1999).

Depolarizing bipolar cells isolated from the retina of goldfish have large synaptic terminals that release glutamate (Tachibana and Okada, 1991) and have proved to be particularly suited to studying various features of ribbon synapses, including fast pha-

\footnotetext{
Received Sept. 20, 2002; revised Jan. 13, 2003; accepted Jan. 15, 2003.

A.L. was supported by a fellowship from the Spanish Ministry of Education, Culture, and Sport (EX2001-46594394)

Correspondence should be addressed to Leon Lagnado, Medical Research Council Laboratory of Molecular Biology, Hills Road, Cambridge CB2 2QH, UK. E-mail: LL1@mrc-Imb.cam.ac.uk.

Copyright $\odot 2003$ Society for Neuroscience $\quad$ 0270-6474/03/232706-09\$15.00/0
}

sic exocytosis (von Gersdorff et al., 1996; Neves and Lagnado, 1999), slower continuous exocytosis (Lagnado et al., 1996), and endocytosis (Neves et al., 2001). Continuous exocytosis is supported by a pool of hundreds of thousands of vesicles, and at any one time, only a small fraction of these are associated with active zones (Lagnado et al., 1996). Total internal reflection fluorescence microscopy has demonstrated that although fast exocytosis is confined primarily to a few specialized sites (probably active zones), slower modes of release can occur at other areas of the presynaptic membrane (Zenisek et al., 2000). This observation raises a number of questions. How many active zones are there in the terminal, and how many vesicles dock to the membrane at these and other sites? If vesicles fuse at sites remote from ribbons, are $\mathrm{Ca}^{2+}$ channels and the calcium-activated potassium $\left(\mathrm{K}_{\mathrm{Ca}}\right)$ channels that associate with them also distributed more widely? Alternatively, is calcium influx confined to active zones? To investigate these questions, we measured exocytosis in small areas of the presynaptic membrane of bipolar cells by making capacitance measurements in cell-attached patches while monitoring the $\mathrm{Ca}^{2+}$-activated $\mathrm{K}^{+}$conductance. Cell-attached capacitance measurements have been used to measure exocytosis in chromaffin cells (Neher and Marty, 1982; Albillos et al., 1997) and pituitary nerve terminals (Klyachko and Jackson, 2002). Here, we demonstrate that this method can also be used to investigate exocytosis and endocytosis triggered by local depolarization of synaptic membrane. Taking advantage of this, we probed the distribution of exocytic sites and ion channels in the presynaptic membrane. We demonstrate that releasable vesicles, $\mathrm{Ca}^{2+}$ channels, and $\mathrm{K}_{\mathrm{Ca}}$ channels are colocalized at specialized sites. These sites had a density similar to that of active zones measured in transmission electron micrographs of isolated cells. We also find 
that equal numbers of vesicles are docked at the active zone and at remote sites of the surface membrane, suggesting that calcium spreading from sites of influx may also trigger exocytosis at longer distances.

\section{Materials and Methods}

Capacitance and conductance measurements in patches of presynaptic membrane. Depolarizing bipolar cells were isolated from the retina of goldfish (Carassius auratus) by enzymatic digestion (Burrone and Lagnado, 1997). Recordings were made using an Axopatch 200A amplifier (Axon Instruments, Foster City, CA) and acquired with a G3 Power Macintosh computer equipped with an ITC-16 interface (Instrutech, Port Washington, NY) controlled by the Pulse Control extension (Horrigan and Bookman, 1994) of Igor Pro software (Wavemetrics, Lake Oswego, OR). The standard extracellular solution contained (in $\mathrm{mM}$ ): $120 \mathrm{NaCl}, 2.5 \mathrm{KCl}, 1 \mathrm{MgCl}_{2}, 2.5 \mathrm{CaCl}_{2}, 10$ glucose, and 10 HEPES, at a $\mathrm{pH}$ of 7.3 and $\sim 270 \mathrm{mOsm} / \mathrm{kg}$. Borosilicate glass pipettes were fire-polished and coated with wax (BDH Chemicals, Poole, UK). Pipette resistances were $2-5 \mathrm{M} \Omega$ when filled with the extracellular solution. Seal resistances for cell-attached recordings were $>5 \mathrm{G} \Omega$. In some experiments, terminals were loaded with the $\mathrm{Ca}^{2+}$ chelator EGTA by incubation in 0.1 or $0.2 \mathrm{mM}$ EGTA-AM (0.1\% DMSO; Molecular Probes, Eugene, OR) for 15-30 min.

Changes in the capacitance of the membrane patch $\left(\Delta C_{\mathrm{m}}\right)$ were made using the piecewise linear technique (Neher and Marty, 1982) with a dual-phase digital lock-in amplifier (model SR850 DSP; Stanford Research Systems, Stanford, CA) controlled through the RS232 interface by macros written in Igor Pro software. A sinusoidal command generated by the lock-in amplifier was added to the command potential generated by the ITC-16 interface using a summing amplifier, both inputs of which could be gated by a transistor-transistor logic (TTL) signal. The peak-to-peak amplitude of the sinusoid was $80 \mathrm{mV}$, and the frequency $(\nu)$ was fixed at $8 \mathrm{kHz}$. The output from the patch-clamp amplifier was low-pass filtered at $12 \mathrm{kHz}$ (four-pole Bessel) before input to the lock-in amplifier. The two orthogonal outputs from the lock-in amplifier were filtered digitally within the instrument ( $3 \mathrm{msec}$ time constant, four-pole Bessel) and acquired at $2 \mathrm{kHz}$. The phase angle $(\alpha)$ of the lock-in amplifier was set using a modification of the fast capacitance compensation circuitry of the patch-clamp amplifier, allowing a $1 \mathrm{fF}$ increase in compensation to be added in response to a TTL signal ("capacitance dither"). An iterative Igor macro compared the signal from the two orthogonal outputs of the lock-in amplifier and corrected $\alpha$ until the capacitance dither was apparent on only one output.

The membrane potential of isolated bipolar cells is likely to "flip" spontaneously from a resting value of approximately -60 up to $-35 \mathrm{mV}$ because of a spontaneously active conductance (Burrone and Lagnado, 1997). The activation threshold of the L-type $\mathrm{Ca}^{2+}$ channels in the terminal conductance is approximately $-42 \mathrm{mV}$, so all patches were held at $65 \mathrm{mV}$ below the resting membrane potential to prevent the possible activation of $\mathrm{Ca}^{2+}$ channels in the patch by the sinusoidal command voltage.

Measuring capacitance changes during depolarization. When capacitance measurements are made in the whole-cell recording configuration, it is usual to turn off the sinusoidal command voltage while the depolarizing stimulus is applied, thereby allowing measurement of the $\mathrm{Ca}^{2+}$ current that triggers exocytosis. Capacitance measurements made while $\mathrm{Ca}^{2+}$ channels are activated are, in any case, likely to be unreliable, because the sinusoidal command voltage opens and closes voltagesensitive channels with a lag (resulting in currents that, like capacitative currents, are out of phase with the sinusoid). One way of minimizing this effect is to use a sinusoid of very high frequency that does not modulate voltage-sensitive conductances significantly (for detailed discussion, see Debus et al., 1995). A practical constraint on this approach is that the signal-to-noise ratio of capacitance measurements is also dependent on the frequency of the sinusoid in relation to the capacitance of the cell (Gillis, 1995). To maximize the quality of the capacitance signal, sinusoid frequencies on the order of $800 \mathrm{~Hz}$ are usually used in whole-cell recordings. These frequencies modulate voltage-sensitive conductances if superimposed on a depolarizing voltage step and lead to artifactual capac-
A

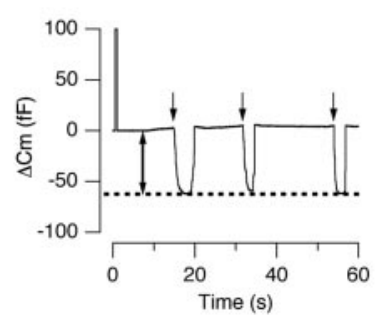

B

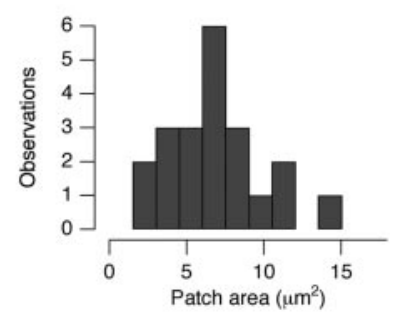

Figure 1. Capacitance of membrane patches. $A$, Measuring capacitance of an inside-out patch. The upward deflection at the beginning of the trace is a calibration dither of $100 \mathrm{fF}$. When the patch was pressed a few micrometers into a piece of Sylgard (arrows), $C_{m}$ decreased, and this value was considered the baseline $C_{m}$. When the pipette was retracted, $C_{m}$ increased by 60 $\mathrm{fF}$, the capacitance of the patch. Similar measurements were obtained when this maneuver was repeated. $B$, Distribution of the area of 21 patches, assuming a specific membrane capacitance of $8 \mathrm{fF} / \mu \mathrm{m}^{2}$. The average patch area was $8.4 \mu \mathrm{m}^{2}$.

itance signals. Frequencies on the order of $10 \mathrm{kHz}$ prevent modulation of voltage-sensitive conductances but cause a very large degradation in the quality of the capacitance signal from whole cells. But the small resting capacitance of a cell-attached patch allows capacitance measurements with a good signal-to-noise ratio to be made with sinusoids of these high frequencies (Debus and Lindau, 2000). We used an $8 \mathrm{kHz}$ sinusoid, which we found provided good separation between capacitance and conductance signals at both the holding potential and depolarized potential (see Results).

Estimating the area of cell-attached patches. To estimate the area of presynaptic membrane in a patch, we measured the capacitance of 21 different patches using the technique described by Sakmann and Neher (1995) and shown in Figure 1 A. The electrode resistance ranged from 2.7 to $5.1 \mathrm{M} \Omega$, with an average value of $4.1 \pm 0.9 \mathrm{M} \Omega$ (mean \pm SEM). After sealing the pipette to the terminal, it was retracted a few micrometers to achieve the inside-out configuration, and changes in capacitance were measured using the lock-in amplifier. A piece of Sylgard was moved toward the pipette, and the tip was pressed a few micrometers into the Sylgard. When the pipette was retracted from the Sylgard, the capacitance increased because of the membrane patch in the tip. This maneuver gave consistent measurements when repeated (Fig. $1 A$ ).

The capacitance of the 21 patches evaluated ranged from 25 to $147 \mathrm{fF}$, with an average value of $67 \pm 3 \mathrm{fF}$ (Fig. $1 B$ ). Assuming a specific membrane capacitance of $8 \mathrm{fF} / \mu \mathrm{m}^{2}$, the average area of the patches was calculated to be $8.4 \mu \mathrm{m}^{2}$. This value is similar to the area of patches obtained from chromaffin cells using pipettes of similar resistances (Sakmann and Neher, 1995). The average capacitance of a terminal is $\sim 3.1 \mathrm{pF}$ (Neves and Lagnado 1999), so we sampled $\sim 2.2 \%$ of the terminal membrane.

Electron microscopy. Isolated retinal bipolar cells were plated onto Permanox dishes and fixed for $10 \mathrm{~min}$ in cold $0.1 \mathrm{M}$ phosphate buffer (PB, $\mathrm{pH} 7.3$ ) containing $1.6 \%$ glutaraldehyde, $1 \%$ paraformaldehyde, $2 \mathrm{~mm}$ $\mathrm{MgCl}_{2}$, and $0.05 \% \mathrm{NaN}_{3}$. After washing in $0.1 \mathrm{M} \mathrm{PB}$, cells were post-fixed for $1 \mathrm{hr}$ in $0.2-0.8 \% \mathrm{OsO}_{4}$ plus $1.5 \% \mathrm{~K}_{4} \mathrm{Fe}(\mathrm{CN})_{6}$ in $0.1 \mathrm{M} \mathrm{PB}$ at $4^{\circ} \mathrm{C}$, washed in $0.1 \mathrm{M}$ PB followed by $0.05 \mathrm{~m}$ Tris maleate buffer (TMB, pH 5.2), and stained with $1 \%$ uranyl acetate in $0.05 \mathrm{TMB}(\mathrm{pH} 6.0)$ for $1 \mathrm{hr}$ at $4^{\circ} \mathrm{C}$. Finally, the cells were washed in $0.05 \mathrm{M} \mathrm{TMB}$ ( $\mathrm{pH}$ 5.2), dehydrated with ethanol, and embedded in Epon 812 (TAAB). Thin sections $(80-100 \mathrm{~nm}$ ) were cut and mounted onto copper grids, stained with uranyl acetate and lead citrate, and examined in a Philips EM208S electron microscope. Electron micrographs were taken at a magnification of $4000-25,000 \times$, scanned at $600-1000 \mathrm{dpi}$, and inverted digitally using Adobe Photoshop software (Adobe Systems, San Jose, CA).

\section{Results}

Capacitance and conductance changes in patches of presynaptic membrane

Capacitance and conductance changes recorded from a patch of membrane on the synaptic terminal of a depolarizing bipolar cell are shown in Figure $2 \mathrm{~A}$. The pipette contained $2.5 \mathrm{mM} \mathrm{Ca}^{2+}$, and 
A

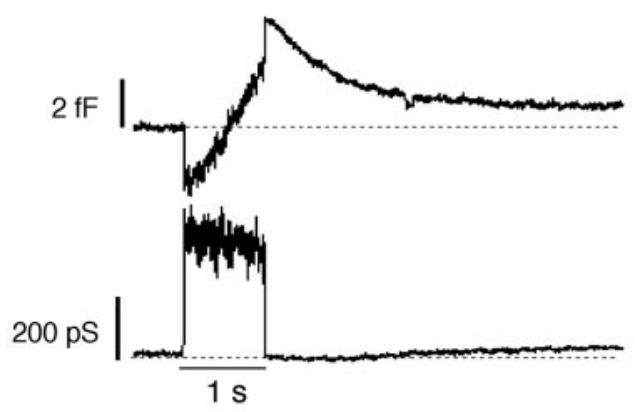

B

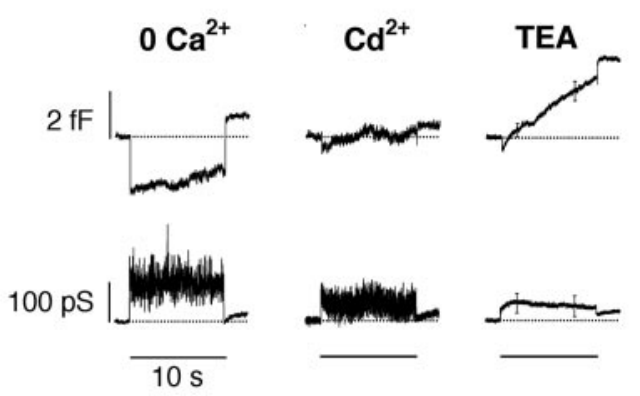

C

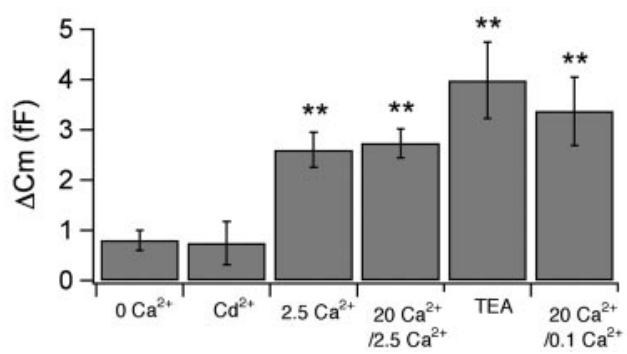

Figure 2. Capacitance and conductance changes in cell-attached patches in response to depolarization. A, Record from a single stimulus delivered with $2.5 \mathrm{~mm} \mathrm{Ca}^{2+}$ in the pipette. Patch was held hyperpolarized at $65 \mathrm{mV}$ from rest and depolarized for $1 \mathrm{sec}$ to a potential $60 \mathrm{mV}$ greater than rest. During the stimulus, the capacitance trace showed a gradual increase, and the conductance trace became noisier. $B$, Single recording of capacitance and conductance obtained with a pipette solution that did not contain $\mathrm{Ca}^{2+}$ (left). Single recording obtained with a pipette

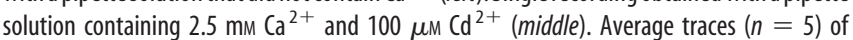
capacitance and conductance changes for membrane patches in which the electrode solution contained $20 \mathrm{~mm} \mathrm{Ca}^{2+}$ and $30 \mathrm{~mm}$ TEA (right). Bars show SEM. Depolarization lasted $10 \mathrm{sec}$ (bar). C, Summary of the capacitance increases obtained at the end of $10 \mathrm{sec}$ depolarizations performed with different pipette solutions (from left to right): $0 \mathrm{~mm} \mathrm{Ca}{ }^{2+}$ and $1 \mathrm{mM} \mathrm{EGTA} \mathrm{(} n=$ 14); $2.5 \mathrm{~mm} \mathrm{Ca}^{2+}$ and $0.1 \mathrm{mmCd}^{2+}(n=6) ; 2.5 \mathrm{~mm} \mathrm{Ca}^{2+}(n=26) ; 20 \mathrm{~mm} \mathrm{Ca}^{2+}(n=15) ; 20$ $\mathrm{mm} \mathrm{Ca}{ }^{2+}$ and $30 \mathrm{~mm}$ TEA $(n=5)$; and $0.1 \mathrm{~mm} \mathrm{Ca}^{2+}$ in the bath and $20 \mathrm{~mm} \mathrm{Ca}^{2+}$ in the pipette $(n=7)$. The degree of significance was at least $p<0.01$, unpaired Student's $t$ test $\left.{ }^{* *}\right)$. Bars show SEM.

the patch was held at $65 \mathrm{mV}$ below the resting membrane potential $\left(V_{\mathrm{m}}\right)$. In this example, depolarization for $1 \mathrm{sec}$ to a potential $60 \mathrm{mV}$ above $V_{\mathrm{m}}$ elicited a capacitance increase $\left(\Delta C_{\mathrm{m}}\right)$ of $5.4 \mathrm{fF}$. The usual method of measuring the capacitance increase caused by a depolarizing stimulus is to monitor capacitance immediately before and after the stimulus and measure the change (Gillis, 1995). In the present experiments, we maintained the sinusoidal command voltage during the depolarizing voltage step that opened $\mathrm{Ca}^{2+}$ channels so as to continue monitoring capacitance and conductance during depolarization of the patch (for a discussion of this approach, see Materials and Methods). The trace
A

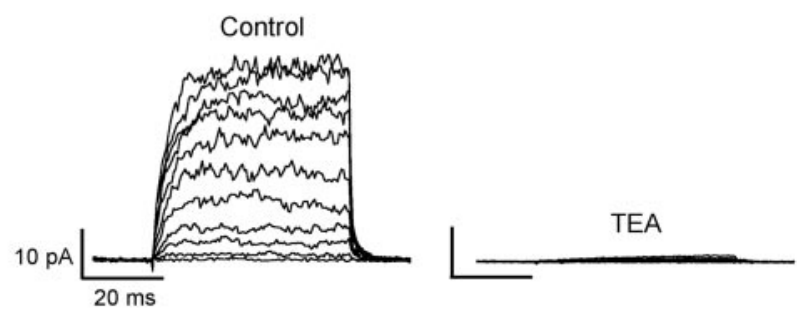

B

C
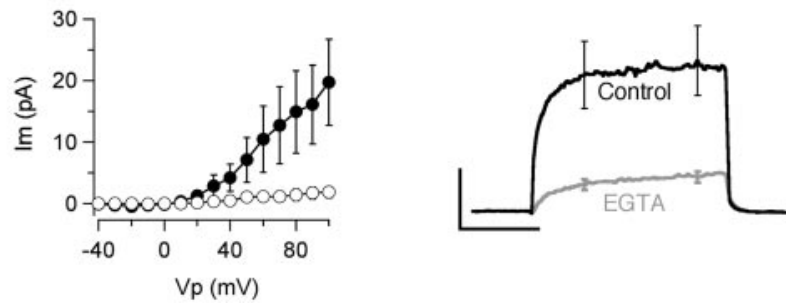

Figure 3. Conductance changes in membrane patches were mediated by $\mathrm{K}_{\mathrm{Ca}}$ channels. $A$, Current traces in response to voltage steps ranging from 0 to $+100 \mathrm{mV}$ relative to the resting membrane potential in $10 \mathrm{mV}$ increments. Each trace is the average of 20 responses. Left, In control conditions. Similar responses were observed in more than $80 \%$ of patches. Right, With addition of $30 \mathrm{~mm}$ TEA to the pipette solution. Outward currents were suppressed in all patches. $B$, Current-voltage relationship for the steady-state current under control conditions (filled circles) and in $30 \mathrm{~mm}$ TEA (open circles). C, Averaged current traces at $+100 \mathrm{mV}$ above the resting membrane potential under control conditions (black trace; four patches) and after loading with EGTA (gray trace; six patches). Bars show SEM.

in Figure $2 A$ shows an immediate downward deflection, which is an artifact associated with the sudden voltage change. The amplitude of this artifact varied in different recordings. The capacitance response in Figure $2 \mathrm{~A}$ could therefore be measured in two ways, as follows: by monitoring the slow capacitance increase occurring during the pulse or by comparing the capacitance signal before and after the pulse. After repolarization, the capacitance recovered by $72 \%$ with a time constant of $0.81 \mathrm{sec}$. The rate of capacitance recovery was similar to the rate of endocytosis measured in whole-cell recordings (von Gersdorff and Matthews, 1994; Neves and Lagnado, 1999).

During the depolarizing stimulus, the conductance of the patch $\left(G_{\mathrm{m}}\right)$ increased and became noisy but then recovered quickly on repolarization (Fig. $2 A$ ). A number of observations indicated that this conductance was a result of $\mathrm{K}_{\mathrm{Ca}}$ channels, which are coupled closely to L-type $\mathrm{Ca}^{2+}$ channels in this synaptic terminal (Burrone et al., 2002). Depolarization of membrane patches evoked noisy outward currents (Fig. $3 A$ ) with the characteristic current-voltage relationship of the $\mathrm{K}_{\mathrm{Ca}}$ conductance (Fig. 3B) (Kaneko and Tachibana, 1985; Burrone and Lagnado, 1997). The conductance was also inhibited by blocking $\mathrm{K}^{+}$channels by adding $30 \mathrm{~mm}$ TEA to the pipette solution (Fig. $3 A, B$ ) and partially inhibited by loading terminals with EGTA (Fig. $3 C$ ). $\mathrm{K}_{\mathrm{Ca}}$ channels are activated synergistically by membrane depolarization and cytoplasmic calcium increases (Hille, 2001). Because of their wide sensitivity to calcium (McManus, 1990), they have been used as reporters of $\mathrm{Ca}^{2+}$ signals close to $\mathrm{Ca}^{2+}$ channels in hair cells (Roberts, 1993; Tucker and Fettiplace, 1996), frog motor neurons (Yazejian et al., 2000), and goldfish bipolar cells (Burrone et al., 2002).

The capacitance and conductance responses evoked by depolarization of the patch were both inhibited when $\mathrm{Ca}^{2+}$ influx 
across the patch was prevented, either by removing $\mathrm{Ca}^{2+}$ from the pipette or by adding $100 \mu \mathrm{M}$ cadmium to block $\mathrm{Ca}^{2+}$ channels (Fig. $2 B, C$ ). Might depolarization of the patch trigger these responses by opening $\mathrm{Ca}^{2+}$ channels outside the patch? To test this possibility, we inhibited $\mathrm{Ca}^{2+}$ influx outside the patch by lowering the $\mathrm{Ca}^{2+}$ concentration in the bath from 2.5 to $0.1 \mathrm{~mm}$ (leaving $20 \mathrm{mM} \mathrm{Ca}^{2+}$ in the pipette). Under these conditions, the capacitance increase triggered by a $10 \mathrm{sec}$ depolarization was maintained (Fig. 2C), indicating that this response was not caused by $\mathrm{Ca}^{2+}$ influx outside the patch. Below, we show that introduction of the calcium buffer EGTA into the cell by incubation in EGTA-AM also inhibited the capacitance increase evoked by depolarization (see Fig. $7 C$ ). We therefore attribute the capacitance response to fusion of synaptic vesicles triggered by the local entry of $\mathrm{Ca}^{2+}$. Although activation of the $\mathrm{K}_{\mathrm{Ca}}$ conductance accompanied the capacitance increase evoked by depolarization, the two signals did not show any obvious degree of correlation, indicating good separation (Fig. $2 A, B$ ). In support of this conclusion, the capacitance response was left intact when the conductance increase was blocked by addition of $30 \mathrm{~mm}$ TEA to the pipette (Fig. $2 B, C$ ).

If exocytosis evoked by depolarization were a result of $\mathrm{Ca}^{2+}$ entry through L-type $\mathrm{Ca}^{2+}$ channels, the size of the capacitance response should depend on the potential to which the membrane is stepped. The amount of exocytosis is expected to increase as the depolarization opens increasing numbers of $\mathrm{Ca}^{2+}$ channels and then decline for stimuli to more positive potentials that approach $\mathrm{E}_{\mathrm{Ca}}$, the reversal potential for $\mathrm{Ca}^{2+}$ ions (Mennerick and Matthews, 1996). Figure $4 A$ shows a test of this prediction, in which a number of capacitance responses to $1 \mathrm{sec}$ depolarizations were applied to the same membrane patch. The largest response was obtained when the membrane was depolarized $60 \mathrm{mV}$ from the resting potential. A depolarization of $140 \mathrm{mV}$ elicited exocytosis at half the rate, whereas a depolarization of $180 \mathrm{mV}$ did not evoke a significant response. Collected results from these experiments are shown in Figure $4 B$, which plots the capacitance increase against the amplitude of the depolarizing step. If the resting membrane potential is taken to be $-60 \mathrm{mV}$, the capacitance response was maximal at $\sim 0 \mathrm{mV}$, which is roughly the potential at which the $\mathrm{Ca}^{2+}$ current is maximal. The capacitance response was almost absent when the membrane was depolarized by 180 $\mathrm{mV}$, which would correspond to a membrane potential of $+120 \mathrm{mV}$. In comparison, $\mathrm{E}_{\mathrm{Ca}}$ was expected to be approximately $+130 \mathrm{mV}$ (with $2.5 \mathrm{mM} \mathrm{Ca}^{2+}$ in the pipette, assuming an internal free $\left[\mathrm{Ca}^{2+}\right]$ of $\left.0.1 \mu \mathrm{M}\right)$. These results are therefore consistent with the conclusion that the capacitance response is caused by $\mathrm{Ca}^{2+}$ influx through the L-type $\mathrm{Ca}^{2+}$ channels that trigger exocytosis from this synaptic terminal (Tachibana and Okada, 1991).

The results in Figures 2-4 provide the first demonstration that exocytosis can be triggered by local depolarization of cellattached patches. Although the cell-attached recording configuration has been used to study spontaneous fusion events in chromaffin cells, it has not yet been possible to evoke exocytosis by local depolarization of the membrane (Albillos et al., 1997). We do not know the reason for this difference between chromaffin cells and bipolar cell terminals. One possibility is that because chromaffin cells lack active zones, the fusion of granules requires the opening of more $\mathrm{Ca}^{2+}$ channels than commonly occur in a small area of membrane. Below, we provide evidence that the ability to trigger exocytosis in patches of presynaptic membrane is a result of the concentration of $\mathrm{Ca}^{2+}$ channels in clusters.

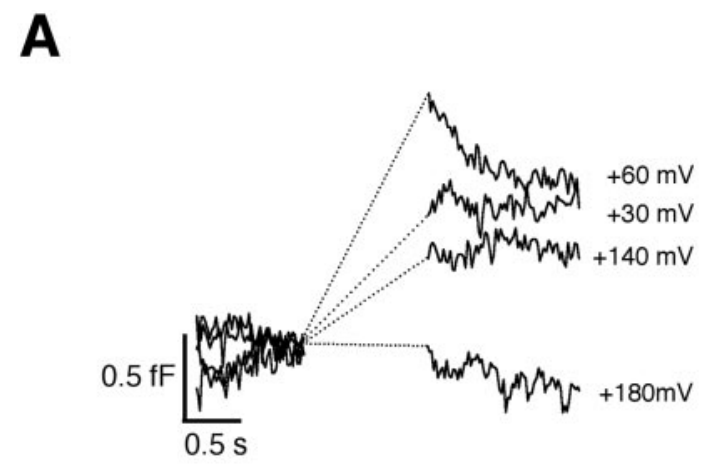

B

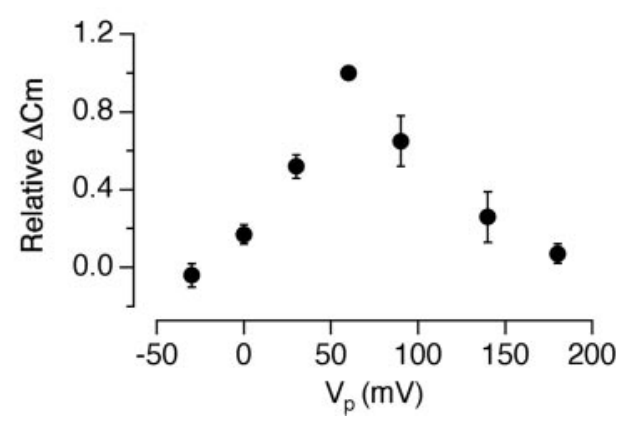

Figure 4. Capacitance responses were dependent on voltage. A, Capacitance responses elicited by a 1 sec depolarization. The amplitude of the voltage step is shown by the corresponding trace. All records from the same patch. The stimuli were applied in the following order: +180 , $+60,+30,+140 \mathrm{mV}$. In these experiments, the sinusoidal voltage was switched off during the depolarizing stimulus to prevent saturation of the amplifier. $B$, The relative amplitude of the capacitance response as a function of the voltage step. Measurements from each patch have been normalized to the response to $\mathrm{a}+60 \mathrm{mV}$ step. Points are averaged from measurements in 5-23 patches. The relationship peaks for a step of $+60 \mathrm{mV}$ and approaches zero for a step of $+180 \mathrm{mV}$. Bars show SEM.
A

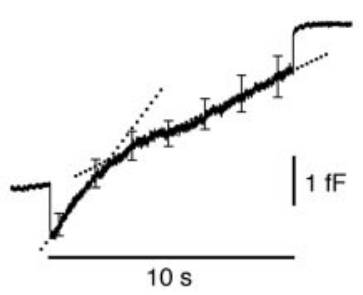

B

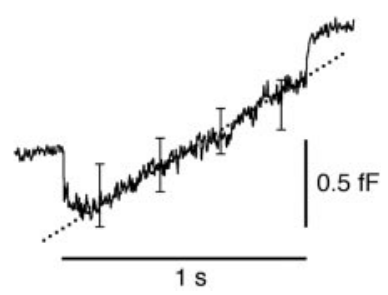

Figure 5. Kinetics of exocytosis in cell-attached patches. A, Average time course of the exocytosis shown by 18 patches during a 10 sec depolarization. There was a delay of $\sim 120 \mathrm{msec}$ before capacitance started to increase at a rate of $0.65 \mathrm{fF} / \mathrm{sec}$, and after $\sim 2.5 \mathrm{sec}$, capacitance slowed to a continuous rate of $0.25 \mathrm{fF} / \mathrm{sec}$. Bars show SEM. $B$, Average time course of the exocytosis shown by 15 patches during a 1 sec depolarization. A delay of $\sim 110 \mathrm{msec}$ can be observed before capacitance started to increase linearly at a rate of $0.86 \mathrm{fF} / \mathrm{sec}$. Bars show SEM.

\section{Kinetics of exocytosis in patches of presynaptic membrane}

The averaged capacitance response to a $10 \mathrm{sec}$ depolarization is shown in Figure $5 A$. After a delay of $\sim 120 \mathrm{msec}$, fast and slow phases of exocytosis were observed. The capacitance rose linearly at a rate of $\sim 0.65 \mathrm{fF} / \mathrm{sec}$ for $\sim 2.5 \mathrm{sec}$ (involving the release of at least 60 vesicles) and then continued to increase at a rate of $\sim 0.25$ $\mathrm{fF} / \mathrm{sec}$ (reflecting exocytosis at a rate of at least 10 vesicles/sec). The initial phase of release is shown more clearly in Figure $5 B$, which is the averaged response to a $1 \mathrm{sec}$ depolarization obtained from 15 patches. In this group of recordings, the first phase of capacitance response occurred at a rate of $0.86 \mathrm{fF} / \mathrm{sec}$. Two obser- 


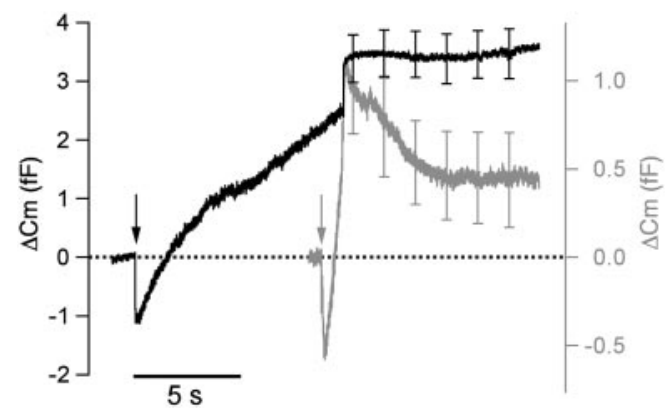

Figure 6. Endocytosis in cell-attached patches. Average time course of the capacitance change in response to depolarizations lasting $10 \mathrm{sec}$ (black trace; $n=18$ ) and $1 \mathrm{sec}$ (gray trace; $n=16$ ). The arrows indicate the beginning of the stimuli. The two responses are drawn so that the ends of the stimuli coincide in time. They are also on different scales to bring the signals at the end of the stimuli into coincidence. Bars show SEM.

vations indicated that the delay between the beginning of the depolarization and the capacitance increase was not because of a slow increase in the free $\mathrm{Ca}^{2+}$ concentration at the membrane. First, the conductance increase was maximal within $\sim 10 \mathrm{msec}$ (Fig. 2). Second, the delay was not affected by loading terminals with EGTA.

The lack of an immediate exocytic response in patches is in striking contrast with measurements in whole terminals, in which a rapidly releasable pool (RRP) of vesicles can be discharged within $20 \mathrm{msec}$ of a strong depolarizing stimulus (Mennerick and Matthews, 1996; Neves and Lagnado, 1999). The lack of rapidly releasable vesicles in patches might reflect their discharge before depolarization by the mechanical distortion of the membrane by the pipette, perhaps in a manner analogous to the calcium-independent discharge of vesicles caused by application of hypertonic solution (Rosenmund and Stevens, 1996). Recruitment of more slowly released vesicles evidently continued to occur in patches. In whole terminals, two phases of release follow discharge of the RRP; the first involves a reserve pool of $\sim 4000$ vesicles, after which continuous exocytosis occurs at a rate of $\sim 1000$ vesicles per second (Neves and Lagnado, 1999). Taking the capacitance of a single vesicle as 26 aF (Neves and Lagnado, 1999), the first phase of release measured in a patch would correspond to a total of $\sim 3000$ vesicles if it occurred similarly over the whole terminal (assuming that the average area of a patch was $2.2 \%$ of the terminal). The second phase of release measured in a patch would correspond to a rate of $\sim 500$ vesicles per second for the whole terminal. The delay between the onset of depolarization and exocytosis in a patch might reflect the time required for new vesicles to be recruited to release sites on the plasma membrane.

\section{Endocytosis in patches of presynaptic membrane}

In whole-cell experiments, exocytosis is followed by complete retrieval of the excess membrane, although the kinetics depend on the duration of the stimulus (von Gersdorff and Matthews, 1994). After a brief stimulus, all the membrane is retrieved with a time constant of 1-2 sec, whereas after a longer stimulus, a proportion is retrieved with a time constant of $10 \mathrm{sec}$ or more (Neves and Lagnado, 1999; Neves et al., 2001). Endocytosis in cellattached patches was also dependent on the duration of the stimulus. Figure 6 compares the recovery phase of averaged responses to depolarizations lasting $1 \mathrm{sec}$ and $10 \mathrm{sec}$. After the $1 \mathrm{sec}$ stimulus, $61 \%$ of the excess membrane was endocytosed with a time constant of $\sim 2 \mathrm{sec}$, so the proportion of fast endocytosis was similar to that in intact terminals (Neves and Lagnado, 1999). The remaining membrane did not show signs of recovery over the next $5 \mathrm{sec}$, indicating that the slow mode of retrieval was strongly inhibited or absent. After a $10 \mathrm{sec}$ stimulus, only $\sim 4 \%$ of the excess membrane was retrieved within $5 \mathrm{sec}$. The kinetics of endocytosis in cell-attached patches were therefore strongly dependent on the duration of the preceding stimulus.

\section{Ca and $\mathrm{K}_{\mathrm{Ca}}$ channels colocalized with areas of exocytosis}

There was a wide variability in the capacitance and conductance responses measured in different patches. Figure $7 A$ shows example traces from three different recordings, in which the membrane was depolarized by $60 \mathrm{mV}$ for $1 \mathrm{sec}$ with $2.5 \mathrm{mM} \mathrm{Ca}^{2+}$ in the pipette. The records at left show no capacitance response and a small conductance increase, the middle records a small capacitance response and larger conductance increase, and the traces at right a large capacitance response also associated with a large conductance increase. Results from a large number of such experiments are shown by the histograms in Figure $7 B$. If the number of $\mathrm{Ca}^{2+}$ channels and $\mathrm{K}_{\mathrm{Ca}}$ channels per unit area of membrane were constant, the conductance increase should be proportional to the area of the patch and therefore mirror the normal distribution in patch area shown in Figure 1. The actual distribution of conductance responses was very different: there was an obvious peak in the distribution at approximately zero, and $\sim 30 \%$ of patches did not demonstrate significant conductance increases (Fig. 7B).

The distribution of capacitance responses measured with 2.5 or $20 \mathrm{mM} \mathrm{Ca}^{2+}$ in the pipette was qualitatively similar to the distribution of conductance responses; there was a peak at zero, indicating that a proportion of patches did not support significant amounts of exocytosis. To establish criteria for counting these patches, the distribution of capacitance responses was also plotted for recordings when $\mathrm{Ca}^{2+}$ influx through voltagesensitive channels was blocked by using pipettes containing 0 $\mathrm{Ca}^{2+}$ and/or $100 \mu \mathrm{M} \mathrm{Cd}^{2+}$. The distribution peaked at approximately zero, and the average response $(0.11 \pm 0.19 \mathrm{fF})$ was not significantly different from zero (Fig. $7 B$ ). The distribution was fit with a Gaussian curve, and the threshold for counting a response as significant set at the mean plus $3 \mathrm{SD}(0.39 \mathrm{fF} / \mathrm{sec})$. By this criterion, $41 \%$ of the patches recorded in the presence of $\mathrm{Ca}^{2+}$ influx did not show significant capacitance responses. This large proportion of "failures" indicates that both exocytic sites and $\mathrm{K}_{\mathrm{Ca}}$ channels coupled to $\mathrm{Ca}^{2+}$ channels were not distributed uniformly in the presynaptic membrane but rather congregated in "hot spots" that were missed in $\sim 40 \%$ of cell-attached recordings.

Figure $7 C$ plots the relationship between the capacitance and conductance increase in the same population of membrane patches. Failure to evoke a conductance increase was correlated with the absence of a capacitance response, indicating that exocytic sites and $\mathrm{K}_{\mathrm{Ca}}$ channels tended to colocalize. These results might be explained if $\mathrm{K}_{\mathrm{Ca}}$ channels coupled to L-type $\mathrm{Ca}^{2+}$ channels were both localized to sites specialized for exocytosis, such as the active zone. The localization of $\mathrm{K}_{\mathrm{Ca}}$ channels and L-type $\mathrm{Ca}^{2+}$ channels occurs at the ribbon synapses of hair cells of the sacculus (Roberts et al., 1990).

The relationship between the rate of exocytosis and conductance increase could be described by a power function with an exponent of 3.9, similar to the relationship between the rate of exocytosis and $\mathrm{Ca}^{2+}$ current in the calyx of Held (Sakaba and Neher, 2001). The coupling between $\mathrm{Ca}^{2+}$ channels, docked vesicles, and $\mathrm{K}_{\mathrm{Ca}}$ channels was investigated further by loading terminals with the calcium buffer EGTA. The protocol we used was 
A

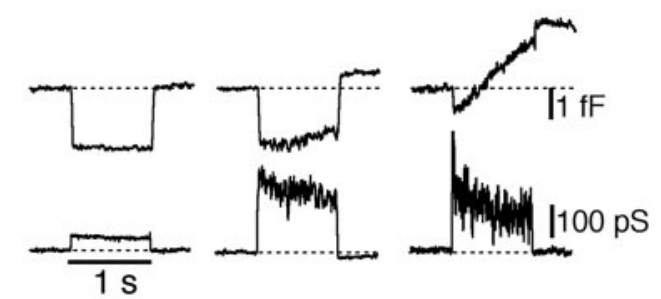

B
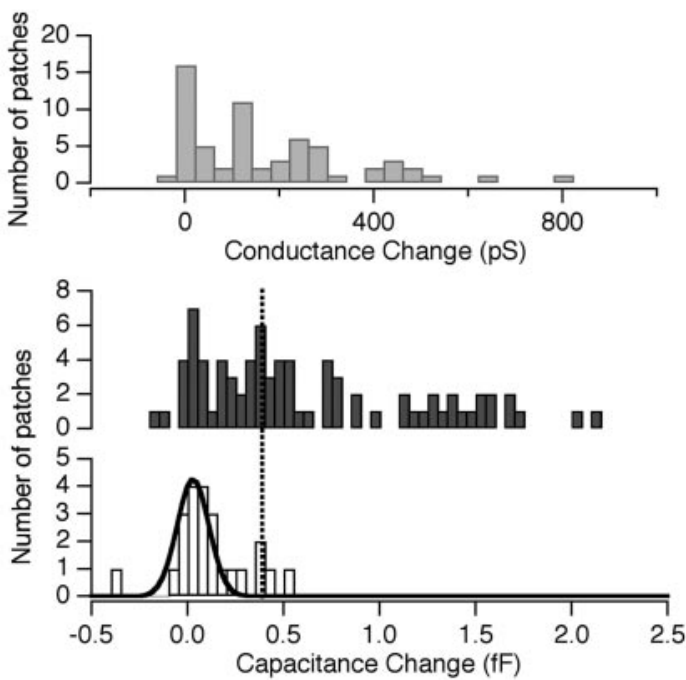

C

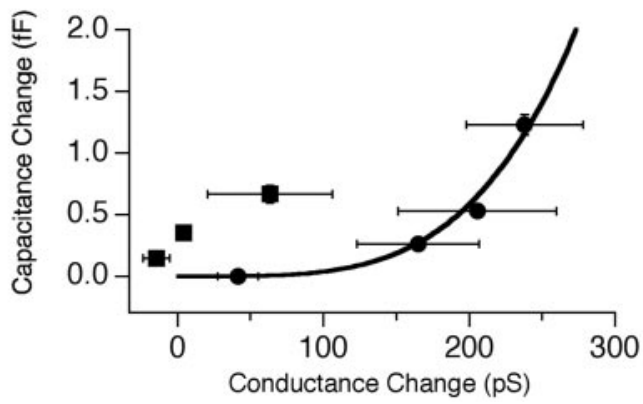

Figure 7. Conductance changes mediated by $\mathrm{K}_{\mathrm{Ca}}$ channels were associated with areas of exocytosis. $A$, Examples of variable capacitance and conductance responses in three different patches. All stimuli were $60 \mathrm{mV}$ steps lasting $1 \mathrm{sec}\left(2.5 \mathrm{~mm} \mathrm{Ca}^{2+}\right.$ in pipette). B, The top histogram shows the distribution of conductance changes obtained during the initial $100 \mathrm{msec}$ of depolarization. The middle histogram plots capacitance measurements obtained with 2.5 or 20 $\mathrm{mm} \mathrm{Ca}{ }^{2+}$ in the pipette after $1 \mathrm{sec}$ depolarization. The bottom histogram plots measurements obtained with $0 \mathrm{Ca}^{2+}$ and/or $100 \mu \mathrm{m} \mathrm{Cd^{2+ }}$ in the pipette after 1 sec depolarization. The Gaussian curve fitted to these measurements has a mean of $0.03 \mathrm{fF}$ and SD of $0.12 \mathrm{fF}$. The dashed line shows the threshold for counting a response as a failure ( $0.39 \mathrm{fF})$. C, Relationship between the capacitance and conductance change in individual patches. Filled circles show measurements under control conditions, binned into groups of 15. Filled squares show measurements after loading with EGTA, binned into groups of 4. The curve describing the circles is a power function with an exponent of 3.9. Bars show SEM.

expected to load cells with at least $10 \mathrm{~mm}$ EGTA (Gomis et al., 1999) and significantly suppressed the activation of $\mathrm{K}_{\mathrm{Ca}}$ channels (Fig. 3C). Figure $7 C$ shows that these quantities of EGTA decreased the exocytic response. EGTA shifted the relationship between the rate of exocytosis and conductance increase to the left, indicating that the activation of $\mathrm{K}_{\mathrm{Ca}}$ channels was more sensitive to the calcium buffer than vesicle fusion. This would be expected
$\mathbf{A i}$

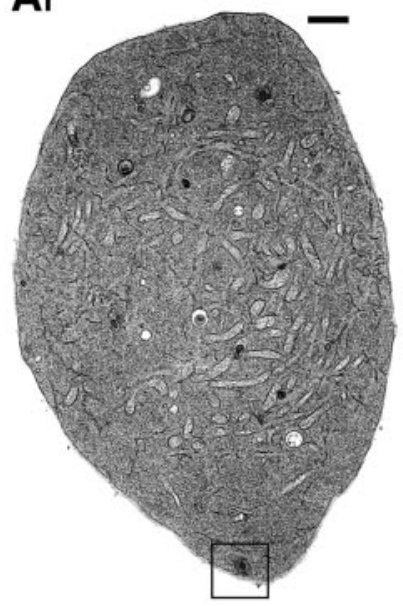

Aii

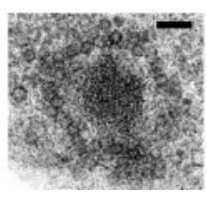

$\mathrm{Bi}$

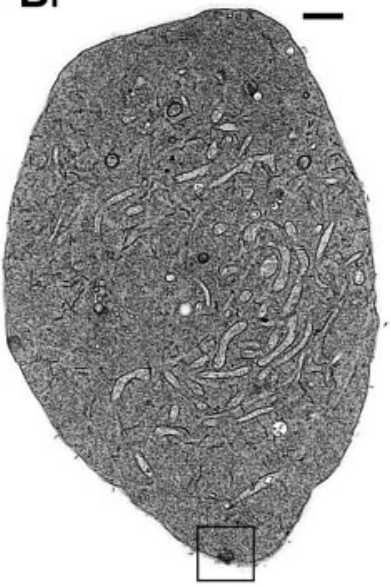

$\mathrm{Bii}_{\mathrm{ii}}$

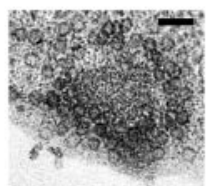

Figure 8. Ribbons appeared in electron micrographs as electron-dense spheres. $A, B$, Electron micrographs of adjacent sections taken from the terminal of an isolated bipolar cell. A single ribbon appears in both sections (inset at higher magnification below) characterized by the halo of synaptic vesicles around an electron-dense spherical structure. Scale bars: $A i$ and $B i$, $1 \mu \mathrm{m}$; Aii and Bii, $300 \mathrm{~nm}$.

if the distance between L-type $\mathrm{Ca}^{2+}$ channels and releasable vesicles were closer than the coupling between L-type $\mathrm{Ca}^{2+}$ channels and $\mathrm{K}_{\mathrm{Ca}}$ channels.

\section{Active zones in the presynaptic terminal of isolated bipolar cells}

The results described above indicate that sites of exocytosis colocalize with $\mathrm{Ca}^{2+}$ channels and $\mathrm{K}_{\mathrm{Ca}}$ channels. Might these specialized sites be active zones? To investigate this possibility, we measured the density of ribbons from transmission electron micrographs of isolated cells. Figure $8, A$ and $B$, shows micrographs of neighboring sections, each $\sim 90 \mathrm{~nm}$ thick. A single ribbon was identifiable, which is boxed and enlarged in the insets. The ribbon appears as an electron-dense sphere surrounded by a dense halo of small vesicles. To calculate the number of ribbons per unit membrane area, we first calculated the density in individual sections. For instance, in Figure $8 B i$, there is a single ribbon identifiable in a membrane area of $39.47 \mu \mathrm{m}$ (the perimeter of the terminal) $\times 0.09 \mu \mathrm{m}$ (the thickness of the section), yielding an apparent density of 0.28 ribbons $/ \mu \mathrm{m}^{2}$. Similar measurements were made in 29 sections obtained randomly from five terminals, containing a total of 26 ribbons. A correction was then made to account for the fact that the average diameter of a ribbon was 436 $\mathrm{nm}$, which would have made it identifiable in $\sim 4$ sections of 90 $\mathrm{nm}$ thickness. The need for this correction is demonstrated in Figure 8, which shows the same ribbon spanning adjacent sections that were selected for this purpose. The mean density of ribbons calculated from individual sections was therefore corrected by a factor of 4 , providing an estimate of $0.10 \pm 0.02$ ribbons $/ \mu \mathrm{m}^{2}$. The average terminal has a capacitance of $3.1 \mathrm{pF}$ (Neves and Lagnado, 1999) and surface area of $\sim 340 \mu \mathrm{m}^{2}$ and would therefore be expected to contain an average of $\sim 34$ ribbons attached to the surface membrane. Imaging of single fusion events in the synaptic terminal of bipolar cells indicates that ves- 


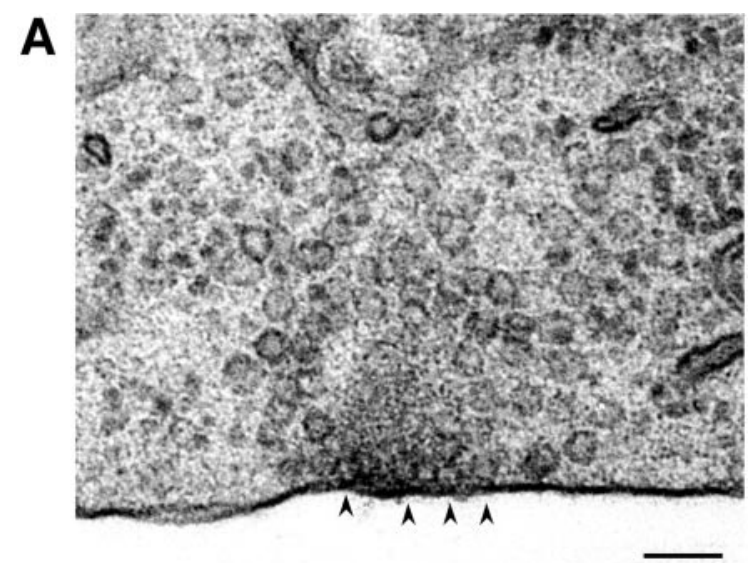

B
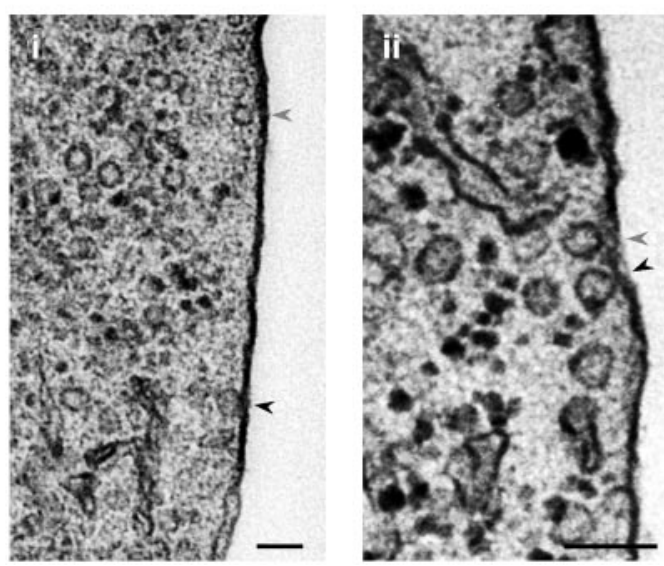

Figure 9. Vesicles were docked on the plasma membrane both at ribbons and at remote sites. Electron micrographs showing vesicles docked at high density under a ribbon $(A)$ and at lower density across the terminal surface $(B)$. Vesicles were classed as docked if there was no discernible cytoplasm between vesicle and plasma membrane: Bi and Bii show two different examples in which the vesicle below (black arrow) but not that above (gray arrow) was counted as docked. Scale bars, $100 \mathrm{~nm}$.

icles may be released rapidly at "preferred" sites with a density of $0.1 / \mu \mathrm{m}$ (Zenisek et al., 2000). The similar density of ribbons in electron micrographs of isolated cells indicates that these preferred sites are active zones.

The average area of a cell-attached patch in this series of experiments was $8.4 \mu \mathrm{m}^{2}$ (Fig. 1), so the mean number of ribbons in a patch was expected to be 0.84 . Assuming that ribbons were distributed randomly, the probability of a patch failing to contain a ribbon will be, according to Poisson statistics, $\exp (-0.84)=$ 0.43 . This figure is consistent with the idea that the $41 \%$ of cellattached patches that failed to show capacitance and conductance responses did not contain an active zone.

\section{Half the docked vesicles occurred away from ribbons}

Might exocytosis be expected to occur at sites remote from active zones? In support of this possibility, we found that a large number of docked vesicles were not associated with ribbons. Figure 9 shows vesicles that seem to be docked to the plasma membrane, at least in a morphological sense. In Figure $9 A$, these vesicles occur at high density immediately under a ribbon, and in Figure $9 B$, docked vesicles are shown remote from a ribbon. The criterion for counting a vesicle as docked was relatively strict: the lack of a discernible space between the vesicle and surface membrane. Thus, of the two examples shown in Figure 9B, only two of the vesicles were counted as docked. The mean number of vesicles counted under a ribbon in a single section $90 \mu \mathrm{m}$ thick was $4 \pm$ 0.8 . The total number of vesicles docked under a single ribbon was therefore estimated as 16 . A terminal with 34 ribbons would therefore contain $\sim 540$ vesicles docked at active zones. The density of vesicles docked at least $0.75 \mu \mathrm{m}$ from the center of a ribbon was $1.47 \pm 0.11 / \mu \mathrm{m}^{2}$, so a terminal with a surface area of 340 $\mu \mathrm{m}^{2}$ would be expected to contain a total of $\sim 500$ vesicles docked away from ribbons.

The relatively high density of vesicles docked all over the surface membrane is also consistent with the observation that vesicle fusion events can occur in areas remote from preferred sites, although at a much slower rate (Zenisek et al., 2000). Our measurements indicate that a cell-attached patch of $8 \mu \mathrm{m}^{2}$ lacking a ribbon would still contain an average of 12 docked vesicles. Why then did $\sim 40 \%$ of patches not generate appreciable capacitance responses? One possibility is that local depolarization of a patch lacking an active zone did not trigger $\mathrm{Ca}^{2+}$ influx. This idea is supported by the observation that patches lacking capacitance responses also lacked a $\mathrm{K}_{\mathrm{Ca}}$ conductance (Fig. $7 C$ ). It is also supported by the observation that calcium influx does not occur all over the surface membrane of the terminal but rather is localized in microdomains that occur at a density of $\sim 0.07 / \mu \mathrm{m}^{2}$ (Beaumont and Lagnado, unpublished observations made by total internal reflection fluorescence microscopy).

\section{Discussion}

We have demonstrated that exocytosis and endocytosis triggered by local depolarization can be recorded in cell-attached patches of presynaptic membrane using the capacitance technique. Two observations indicated that sites of exocytosis in bipolar cells colocalized with $\mathrm{Ca}^{2+}$ channels and $\mathrm{K}_{\mathrm{Ca}}$ channels; the initial rate of exocytosis was correlated with the activation of $\mathrm{K}_{\mathrm{Ca}}$ channels, and exocytosis did not occur in patches lacking these channels. The density of ribbons at the plasma membrane estimated from electron micrographs of isolated cells was consistent with the idea that $\mathrm{Ca}^{2+}$ channels and $\mathrm{K}_{\mathrm{Ca}}$ channels localized at active zones, as suggested for hair cells (Roberts et al., 1990). However, we cannot rule out the possibility that the similar density of ribbons and $\mathrm{Ca}^{2+}$ channels clusters is a coincidence and that clusters of $\mathrm{Ca}^{2+}$ channels occur at nonribbon sites. The clearest way to differentiate between these possibilities might be to image ribbons and sites of $\mathrm{Ca}^{2+}$ influx simultaneously.

\section{Capacitance measurements in cell-attached patches}

The capacitance technique provides time-resolved measurements of exocytosis and endocytosis and has been used widely on a number of preparations, including bovine chromaffin cells (Neher and Zucker, 1993), rat pituitary nerve terminals (Lindau et al., 1992), melanotrophs (Parsons et al., 1995), frog hair cells (Moser and Beutner, 2000), and goldfish retinal bipolar cells (von Gersdorff and Matthews, 1994). Cell-attached recordings increase the resolution of the method to allow measurement of the fusion of single granules in chromaffin cells. However, it has not been possible to trigger exocytosis by depolarization of the patch, making it necessary to record continuously and catch spontaneous fusion events (Albillos et al., 1997; Henkel et al., 2000). Almost all studies of exocytosis and endocytosis triggered by depolarization have therefore been performed in the whole-cell configuration. Recently, Klyachko and Jackson (2002) stimulated exocytosis in pituitary nerve terminals by global depolarization in high- $\mathrm{K}^{+}$medium and resolved the capacitance steps associated with small vesicles. The present study provides the first demon- 
stration that cell-attached capacitance measurements can also be used to measure exocytosis and endocytosis triggered by local depolarization of presynaptic membrane. We did not attempt to maximize the signal-to-noise ratio of our recordings by reducing the depth of electrode immersion and covering the surface of the bathing medium with oil (Rae and Levis, 1992), but it might be expected that these improvements will allow the fusion of single small vesicles to be resolved (Klyachko and Jackson, 2002).

An important advantage of the approach we describe is the ability to monitor exocytosis during a depolarizing stimulus. The use of high-frequency sinusoids when making cell-attached recordings minimizes artifacts caused by the opening of voltagesensitive conductances (Debus et al., 1995). Taking advantage of this, we were able to probe the distribution of exocytic sites and ion channels in the presynaptic membrane. Our results indicate that the triggering of exocytosis by local depolarization of a patch occurs only if that piece of membrane contains a site with a high density of $\mathrm{Ca}^{2+}$ channels and $\mathrm{K}_{\mathrm{Ca}}$ channels, perhaps associated with the active zone containing a ribbon. The inability to trigger the fusion of granules in chromaffin cells by local depolarization might reflect the lack of an active zone (Chow et al., 1996). Calcium imaging of chromaffin cells has not revealed clear $\mathrm{Ca}^{2+}$ microdomains of the type thought to exist in synaptic terminals (Robinson et al., 1995; Neher, 1998).

Capacitance measurements in the whole-cell configuration demonstrate that a rapidly releasable pool of vesicles can be released completely by depolarizations as short as $10 \mathrm{msec}$ (Gomis et al., 1999). We were not able to measure this very rapid form of exocytosis in cell-attached patches. One possibility is that fast release requires the opening of $\mathrm{Ca}^{2+}$ channels over a larger area of the presynaptic membrane, but we think this unlikely because the $\mathrm{Ca}^{2+}$ signal triggered by depolarization of a patch caused the opening of $\mathrm{K}_{\mathrm{Ca}}$ channels. It seems more likely that the formation of a cell-attached patch interfered with rapid exocytosis, perhaps because of the mechanical distortion of the membrane surface. Membrane distortion is thought to underlie the effects of hypertonic solution on hippocampal synapses, in which $\mathrm{Ca}^{2+}$ independent exocytosis of the rapidly releasable pool is followed by strong depression of evoked release (Rosenmund and Stevens, 1996).

A striking observation was the partial block of endocytosis in cell-attached patches (Fig. 6). The kinetics of endocytosis in chromaffin cells and pituitary nerve terminals are also altered in cellattached measurements; both these preparations show full retrieval of excess membrane in whole-cell recordings (Hsu and Jackson, 1996; Smith and Neher, 1997), but the large majority of fusion events in cell-attached patches are irreversible (Ales et al., 1999; Klyachko and Jackson, 2002). The amount of endocytosis in cell-attached recordings from bipolar cell terminals was reduced strongly after a longer stimulus (Fig. 6) in a manner reminiscent of the shift from fast to slow modes of endocytosis observed in whole-cell recordings (Neves and Lagnado, 1999). These results suggest that the slow mode of endocytosis is particularly susceptible to block in cell-attached patches, perhaps because of mechanical distortion of the membrane. A comparison with observations made in chromaffin cells and pituitary nerve terminals indicates that disruption of normal endocytosis is a general feature of cell-attached recordings.

\section{Functional similarities between the active zones of bipolar cells and hair cells}

Colocalization of L-type $\mathrm{Ca}^{2+}$ channels and $\mathrm{K}_{\mathrm{Ca}}$ channels at the active zone has been found at the ribbon synapse of hair cells, the sensory neurons involved in hearing and balance (Roberts et al., 1990). The combination of $\mathrm{Ca}^{2+}$ channels and $\mathrm{K}_{\mathrm{Ca}}$ channels underlies electrical resonance in hair cells (Issa and Hudspeth, 1994; Fettiplace and Fuchs, 1999) and retinal bipolar cells (Burrone and Lagnado, 1997). Other functional similarities between the two types of neuron include spherical dense bodies at the active zone (Lenzi et al., 1999) (Figs. 8, 9), high capacity of mobile calcium buffers (Roberts, 1993; Burrone et al., 2002), and very rapid release of neurotransmitter (Mennerick and Matthews, 1996; Moser and Beutner, 2000). $\mathrm{K}_{\mathrm{Ca}}$ channels also colocalize with $\mathrm{Ca}^{2+}$ channels at the synaptic varicosities of frog motor neurons (Yazejian et al., 2000), a "classic" synapse in which exocytosis is triggered by the action potential. At each of these three synapses, $\mathrm{K}_{\mathrm{Ca}}$ channels have been used as reporters of the $\mathrm{Ca}^{2+}$ signal experienced by synaptic vesicles close to $\mathrm{Ca}^{2+}$ channels (Roberts, 1993; Tucker and Fettiplace, 1996; Yazejian et al., 2000; Burrone et al., 2002). The results we have presented provide support for this approach by demonstrating directly that exocytosis occurs preferentially at sites of $\mathrm{K}_{\mathrm{Ca}}$ channel activation.

The density of active zones in electron micrographs of thin sections yielded an average of $\sim 34$ ribbons per terminal. The total $\mathrm{Ca}^{2+}$ current in a bipolar cell terminal is generally on the order of 100-200 pA at $-10 \mathrm{mV}$ (Neves et al., 2001), so if all the $\mathrm{Ca}^{2+}$ channels were localized to active zones, then each would carry a maximum current of 3-6 pA. In comparison, frog hair cells have $\sim 19$ active zones, and freeze-fracture electron microscopy demonstrates $\sim 130$ particles at each. Approximately 90 of these particles are thought to be $\mathrm{Ca}^{2+}$ channels that support a $\mathrm{Ca}^{2+}$ current of $16 \mathrm{pA}$ at a membrane potential of $-14 \mathrm{mV}$ (Roberts et al., 1990). The remaining 40 particles are thought to be $\mathrm{K}_{\mathrm{Ca}}$ channels. The larger $\mathrm{Ca}^{2+}$ current at active zones of frog hair cells might reflect the larger dense bodies, under which there are $\sim 32$ docked vesicles (Lenzi et al., 1999), twice the number in goldfish bipolar cells. The spatial relationship between $\mathrm{Ca}^{2+}$ channels and docked vesicles is key to understanding the control of exocytosis at the synapse, but it cannot be assumed to be fixed (Atwood and Karunanithi, 2002). A number of lines of evidence indicate that the coupling between $\mathrm{Ca}^{2+}$ channels and docked vesicles is variable at both the bipolar cell synapse (Burrone and Lagnado, 2000; Burrone et al., 2002) and the calyx of Held (Borst and Sakmann, 1996; Sakaba and Neher, 2001). To obtain a fuller understanding of fast exocytosis at the synapse, it will be important to have more detailed ultrastructural information about the spatial relationship between $\mathrm{Ca}^{2+}$ channels and docked vesicles and more direct measurements of the $\mathrm{Ca}^{2+}$ signal at the active zone. Given the large number of vesicles docked to the plasma membrane at sites remote from the active zone (Fig. 9), it will also be important to understand how $\mathrm{Ca}^{2+}$ spreads away from sites of influx to other areas of the surface membrane.

\section{References}

Albillos A, Dernick G, Horstmann H, Almers W, Alvarez de Toledo G, Lindau M (1997) The exocytotic event in chromaffin cells revealed by patch amperometry. Nature 389:509-512.

Ales E, Tabares L, Poyato JM, Valero V, Lindau M, Alvarez de Toledo G (1999) High calcium concentrations shift the mode of exocytosis to the kiss-and-run mechanism. Nat Cell Biol 1:40-44.

Atwood HL, Karunanithi S (2002) Diversification of synaptic strength: presynaptic elements. Nat Rev Neurosci 3:497-516.

Borst JG, Sakmann B (1996) Calcium influx and transmitter release in a fast CNS synapse. Nature 383:431-434.

Burns ME, Augustine GJ (1995) Synaptic structure and function: dynamic organization yields architectural precision. Cell 83:187-194.

Burrone J, Lagnado L (1997) Electrical resonance and $\mathrm{Ca}^{2+}$ influx in the 
synaptic terminal of depolarizing bipolar cells from the goldfish retina. J Physiol (Lond) 505:571-584.

Burrone J, Lagnado L (2000) Synaptic depression and the kinetics of exocytosis in retinal bipolar cells. J Neurosci 20:568-578.

Burrone J, Neves G, Gomis A, Cooke A, Lagnado L (2002) Endogenous calcium buffers regulate fast exocytosis in the synaptic terminal of retinal bipolar cells. Neuron 33:101-112.

Chow RH, Klingauf J, Heinemann C, Zucker RS, Neher E (1996) Mechanisms determining the time course of secretion in neuroendocrine cells. Neuron 16:369-376.

Debus K, Lindau M (2000) Resolution of patch capacitance recordings and of fusion pore conductances in small vesicles. Biophys J 78:2983-2997.

Debus K, Hartmann J, Kilic G, Lindau M (1995) Influence of conductance changes on patch clamp capacitance measurements using a lock-in amplifier and limitations of the phase tracking technique. Biophys J 69:2808-2822.

Fettiplace R, Fuchs PA (1999) Mechanisms of hair cell tuning. Annu Rev Physiol 61:809-834.

Gillis K (1995) Techniques for membrane capacitance measurements. In: Single channel recording, Ed 2 (Sakmann B, Neher E, eds), pp 155-197. New York: Plenum.

Gomis A, Burrone J, Lagnado L (1999) Two actions of calcium regulate the supply of releasable vesicles at the ribbon synapse of retinal bipolar cells. J Neurosci 19:6309-6317.

Gray EG, Pease HL (1971) On understanding the organisation of the retinal receptor synapses. Brain Res 35:1-15.

Henkel AW, Meiri H, Horstmann H, Lindau M, Almers W (2000) Rhythmic opening and closing of vesicles during constitutive exo- and endocytosis in chromaffin cells. EMBO J 19:84-93.

Hille B (2001) Ion channels of excitable membranes, Ed 3. Sunderland, MA: Sinauer Associates.

Horrigan FT, Bookman RJ (1994) Releasable pools and the kinetics of exocytosis in adrenal chromaffin cells. Neuron 13:1119-1129.

Hsu SF, Jackson MB (1996) Rapid exocytosis and endocytosis in nerve terminals of the rat posterior pituitary. J Physiol 494:539-553.

Issa NP, Hudspeth AJ (1994) Clustering of $\mathrm{Ca}^{2+}$ channels and $\mathrm{Ca}^{2+}$ activated $\mathrm{K}^{+}$channels at fluorescently labeled presynaptic active zones of hair cells. Proc Natl Acad Sci USA 91:7578-7582.

Kaneko A, Tachibana M (1985) A voltage-clamp analysis of membrane currents in solitary bipolar cells dissociated from Carassius auratus. J Physiol (Lond) 358:131-152.

Klyachko VA, Jackson MB (2002) Capacitance steps and fusion pores of small and large-dense-core vesicles in nerve terminals. Nature 418:89-92.

Lagnado L, Gomis A, Job C (1996) Continuous vesicle cycling in the synaptic terminal of retinal bipolar cells. Neuron 17:957-967.

Lenzi D, Runyeon JW, Crum J, Ellisman MH, Roberts WM (1999) Synaptic vesicle populations in saccular hair cells reconstructed by electron tomography. J Neurosci 19:119-132.

Lindau M, Stuenkel EL, Nordmann JJ (1992) Depolarization, intracellular calcium and exocytosis in single vertebrate nerve endings. Biophys J 61:19-30.

McManus OB (1990) Calcium-activated potassium channels: regulation by calcium. J Bioenerg Biomembr 23:537-560.

Mennerick S, Matthews G (1996) Ultrafast exocytosis elicited by calcium current in synaptic terminals of retinal bipolar neurons. Neuron 17:1241-1249.
Moser T, Beutner D (2000) Kinetics of exocytosis and endocytosis at the cochlear inner hair cell afferent synapse of the mouse. Proc Natl Acad Sci USA 97:883-888.

Neher E (1998) Vesicle pools and $\mathrm{Ca}^{2+}$ microdomains: new tools for understanding their roles in neurotransmitter release. Neuron 20:389-399.

Neher E, Marty A (1982) Discrete changes of cell membrane capacitance observed under conditions of enhanced secretion in bovine adrenal chromaffin cells. Proc Natl Acad Sci USA 79:6712-6716.

Neher E, Zucker RS (1993) Multiple calcium-dependent processes related to secretion in bovine chromaffin cells. Neuron 10:21-30.

Neves G, Lagnado L (1999) The kinetics of exocytosis and endocytosis in the synaptic terminal of goldfish retinal bipolar cells. J Physiol (Lond) 515:181-202.

Neves G, Gomis A, Lagnado L (2001) Calcium influx selects the fast mode of endocytosis in the synaptic terminal of retinal bipolar cells. Proc Natl Acad Sci USA 98:15282-15287.

Parsons TD, Coorssen JR, Horstmann H, Almers W (1995) Docked granules, the exocytic burst, and the need for ATP hydrolysis in endocrine cells. Neuron 15:1085-1096.

Rae JL, Levis RA (1992) A method for exceptionally low noise single channel recordings. Pflügers Arch 420:618-620.

Rieke F, Schwartz EA (1994) A cGMP-gated current can control exocytosis at cone synapses. Neuron 13:863-873.

Roberts WM (1993) Spatial calcium buffering in saccular hair cells. Nature 363:74-76.

Roberts WM, Jacobs RA, Hudspeth AJ (1990) Colocalization of ion channels involved in frequency selectivity and synaptic transmission at presynaptic active zones of hair cells. J Neurosci 10:3664-3684.

Robinson IM, Finnegan JM, Monck JR, Wightman RM, Fernandez JM (1995) Colocalization of calcium entry and exocytotic release sites in adrenal chromaffin cells. Proc Natl Acad Sci USA 92:2474-2478.

Rosenmund C, Stevens CF (1996) Definition of the readily releasable pool of vesicles at hippocampal synapses. Neuron 16:1197-1207.

Sakaba T, Neher E (2001) Quantitative relationship between transmitter release and calcium current at the calyx of Held synapse. J Neurosci 21:462-476.

Sakmann B, Neher E (1995) Geometric parameters of pipettes and membrane patches. In: Single channel recording, Ed 2 (Sakmann B, Neher E, eds), pp 637-650. New York: Plenum.

Smith C, Neher E (1997) Multiple forms of endocytosis in bovine adrenal chromaffin cells. J Cell Biol 139:885-894.

Tachibana M, Okada T (1991) Release of endogenous excitatory amino acids from ON-type bipolar cells isolated from the goldfish retina. J Neurosci 11:2199-2208.

Tucker TR, Fettiplace R (1996) Monitoring calcium in turtle hair cells with a calcium-activated potassium channel. J Physiol 494:613-626.

von Gersdorff H, Matthews G (1994) Dynamics of synaptic vesicle fusion and membrane retrieval in synaptic terminals. Nature 367:735-739.

von Gersdorff H, Vardi E, Matthews G, Sterling P (1996) Evidence that vesicles on the synaptic ribbon of retinal bipolar neurons can be rapidly released. Neuron 16:1221-1227.

Yazejian B, Sun XP, Grinnell AD (2000) Tracking presynaptic $\mathrm{Ca}^{2+}$ dynamics during neurotransmitter release with $\mathrm{Ca}^{2+}$-activated $\mathrm{K}^{+}$channels. Nat Neurosci 3:566-571.

Zenisek D, Steyer JA, Almers W (2000) Transport, capture and exocytosis of single synaptic vesicles at active zones. Nature 406:849-854. 